\title{
Improvement of Rigid Conductor Lines
}

\author{
Tsuyoshi MANDAI \\ Researcher, \\ Satoshi HARADA \\ Contact Line Structures, Power Supply Technology Div.
}

\author{
Masatoshi SHIMIZU \\ Assistant Senior Researcher, Contact Line Structures, Power Supply Technology Div.
}

Masumi YAMAKAWA

Former Researcher, Contact Line Structures, Power Supply Technology Div.

Rigid conductor lines are currently used in wide ranges by subways and other railways. It is thought that the quality of current collection of rigid conductor lines is influenced by the unevenness of contact surface. Then, we developed a grinding machine to evenly smooth the contact surface. We also installed rigid conductor lines on the current collection testing equipment at the Railway Technical Research Institute, and examined the relation between contact surface and contact loss. Consequently, we confirmed that it was possible to reduce contact loss effectively by using the grinding machine.

Keywords : rigid conductor lines, grinding machine, contact loss, current collection, low cost maintenance

\section{Introduction}

The rigid conductor lines feature a large current capacity, small amounts of wear and easy maintenance, when compared with the catenary system. The rigid conductor lines may be used in urban tunnel and mountain tunnel other than subways from now on. For that purpose, a capacity for high-speed current collection is required for rigid conductor lines. In current collection, rigid conductor lines do not have elasticity against pantographs. In high speed operation, the quality of current collection is influenced by the unevenness of contact surface to increase contact loss. Then, rigid conductor line has to flatten the uneven contact surface and improve the quality of current collection. We developed a grinding machine which evenly smooth the unevenness of contact surface.

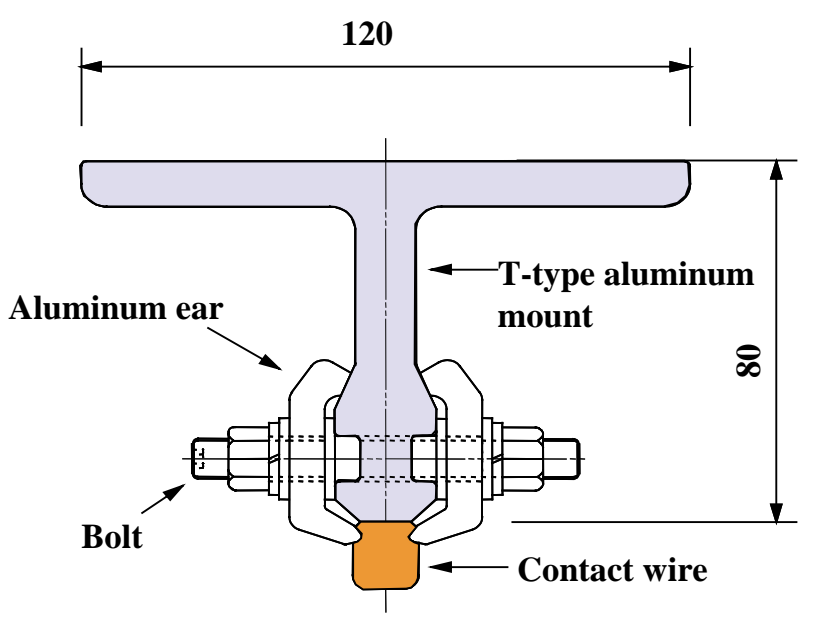

(mm)

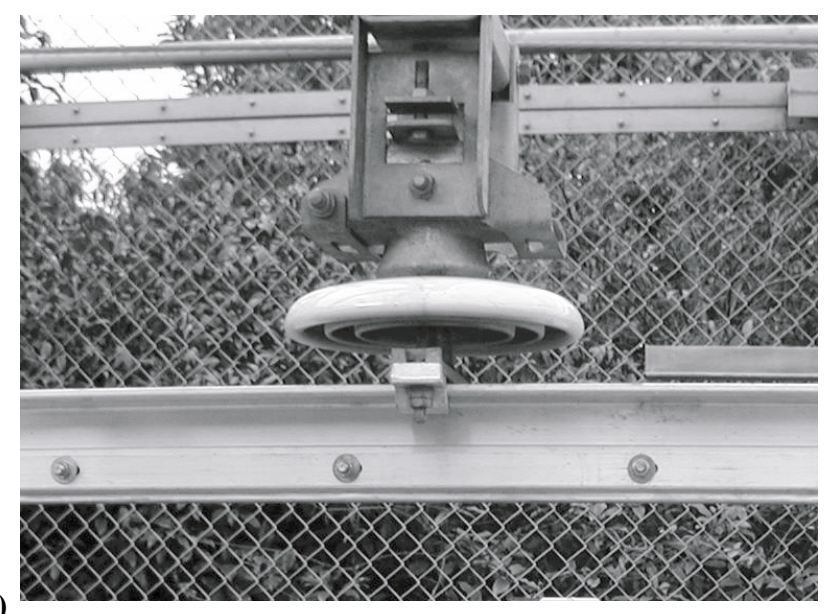

Fig. 1 Structure of T-type cross-section rigid conductor lines

\section{Structure of rigid conductor lines}

We can classify overhead rigid conductor system into two types. One is the T-type cross-section rigid conductor lines attached with a contact wire on the undersurface of mount, and the other is rail type rigid conductor lines that do not use a contact wire. Figures 1 and 2 show the T-type cross-section rigid conductor lines, and the rail type rigid conductor lines, respectively. Although the Ttype cross-section rigid conductor lines can make the unevenness of contact surface smaller, the contact wire must be replaced, if wear of contact wire advances. In the case of the rail type rigid conductor lines, on the other hand, the unevenness of contact surface at installation is thought to be comparatively large, although replacement of the contact wire is not required. 

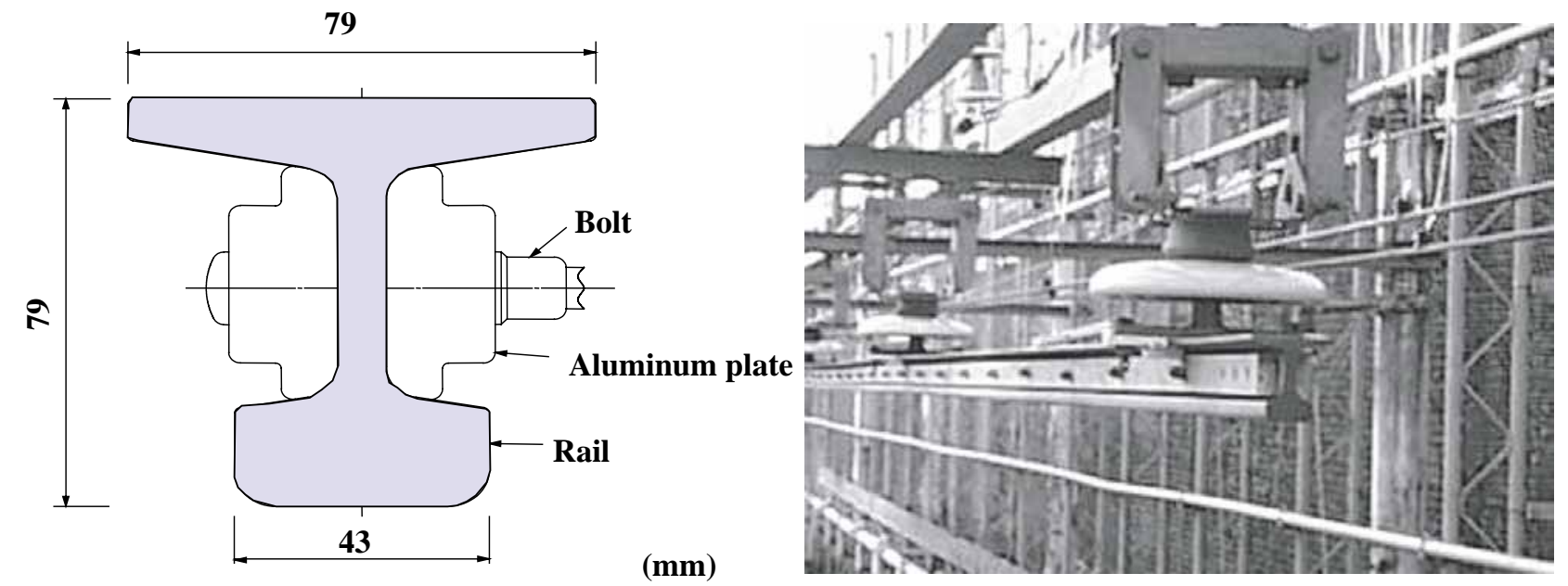

Fig. 2 Structure of Rail type rigid conductor lines

\section{Types of the unevenness of contact surface}

Table 1 shows the conceivable types of the unevenness of contact surface of rigid conductor lines. The grinding machine can smooth the minute unevenness of contact surface, but not that of contact surface due to deflection or irregularities at support points. The contact loss by the unevenness of contact surface of welded joint is reported for the rail type rigid conductor lines. If such unevenness of contact surfaces can be ground, train speed can be raised.

Moreover, generation of corrugations is also reported for the case of a rigid conductor line. Then, we use the grinding machine for the maintenance to grind corrugation.

\section{Specifications of the grinding machine}

Table 2 shows the specifications of the grinding machine, and Fig. 4 its constitution. The grinding system uses a grindstone normally used for copper and iron. The grinding machine can smooth the unevenness continuously. The grinding machine is mounted on a maintenance car that runs for grinding operation at about $3 \mathrm{~km} /$

Table 1 Types of unevenness

\begin{tabular}{|c|c|c|c|}
\hline Types of unevenness & $\begin{array}{c}\text { Grinding } \\
\text { object }\end{array}$ & $\begin{array}{c}\text { T-type cross- } \\
\text { section rigid } \\
\text { conductor lines }\end{array}$ & $\begin{array}{c}\text { Rail type rigid } \\
\text { conductor } \\
\text { lines }\end{array}$ \\
\hline $\begin{array}{c}\text { Irregularity of support } \\
\text { position }\end{array}$ & Impossible. & Exists. & Exists. \\
\hline Deflection & Impossible. & Exists. & Exists. \\
\hline $\begin{array}{c}\text { Minute unevenness at the } \\
\text { time of manufacture }\end{array}$ & possible. & Rarely exists. & Exists. \\
\hline $\begin{array}{c}\text { Minute unevenness at the } \\
\text { time of construction }\end{array}$ & possible. & Rarely exists. & Exists. \\
\hline $\begin{array}{c}\text { Unevenness of welded joint } \\
\text { Small unevenness by } \\
\text { winding peculiarity }\end{array}$ & possible. & Rarely exists. & Exists. \\
\hline $\begin{array}{c}\text { Corrugations, unevenness } \\
\text { of after train running }\end{array}$ & possible. & May exist. & May exist. \\
\hline
\end{tabular}

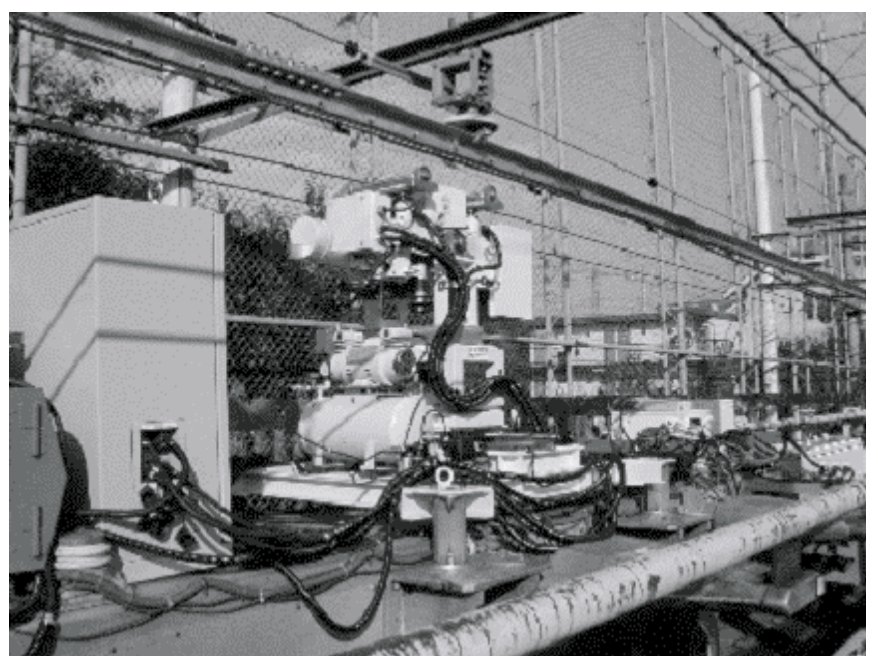

Fig.3 Grinding machine

h. To install rigid conductor lines, the following shall be taken into consideration.

(1) Irregularities of support height, changes in the height of contact surface by deflection, and changes in the inclination

(2) Changes in the deviation in the lateral direction

For (1), the grinding machine has a mechanism to move up and down, and a mechanism with a rotation axis which follows the inclination of the unevenness of con-

Table 2 Specifications of grinding machine

\begin{tabular}{|l|l|}
\hline \multicolumn{1}{|c|}{ Item } & \multicolumn{1}{c|}{ Specifications } \\
\hline Grinding system & Wheel system \\
\hline Types of wheels & For copper, iron \\
\hline Amount of vertical movements & $400 \mathrm{~mm}$ \\
\hline $\begin{array}{l}\text { Amount of right and left deviation } \\
\text { movements }\end{array}$ & $600 \mathrm{~mm}$ \\
\hline Grinding pressure & $0 \sim 500 \mathrm{~N}$ \\
\hline Amount of cutting control & $0.02 \mathrm{~mm}$ \\
\hline Mass & About $400 \mathrm{~kg}$ \\
\hline Grinding speed & About $3 \mathrm{~km} / \mathrm{h}$ \\
\hline
\end{tabular}




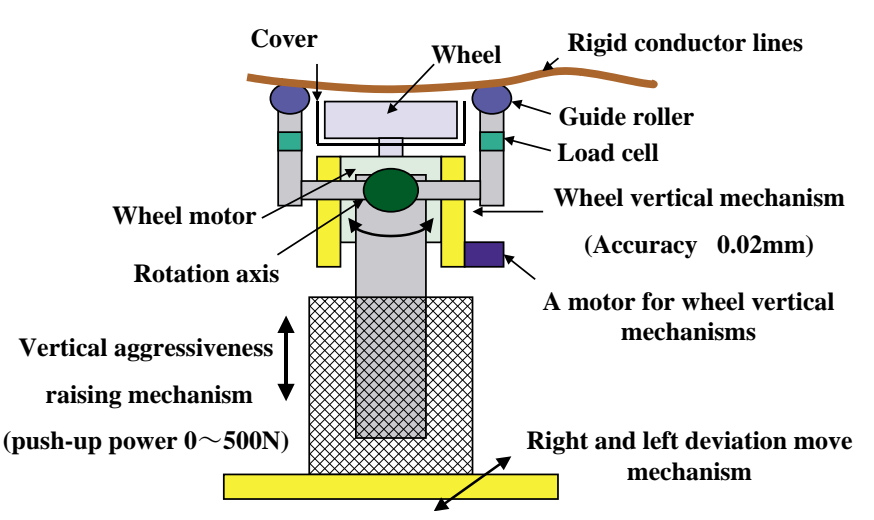

Fig. 4 Constitution of the grinding machine

tact surface. For (2), it has a mechanism to move in the direction of deviation. The machine has the maximum grinding power of about $500 \mathrm{~N}$, and can control the minimum grinding amount of $0.02 \mathrm{~mm}$.

\section{Effect to improve the quality of current collection}

\subsection{T-type cross-section rigid conductor lines}

We installed the T-type cross-section rigid conductor lines on the current collection testing equipment at the Railway Technical Research Institute, and measured the contact loss ratio at different speeds. Figure 5 shows the test results. Consequently, the contact loss ratio was less than $2 \%$ at the speed below $150 \mathrm{~km} / \mathrm{h}$ on a new contact wire, and less than $3 \%$ at the speed above 150

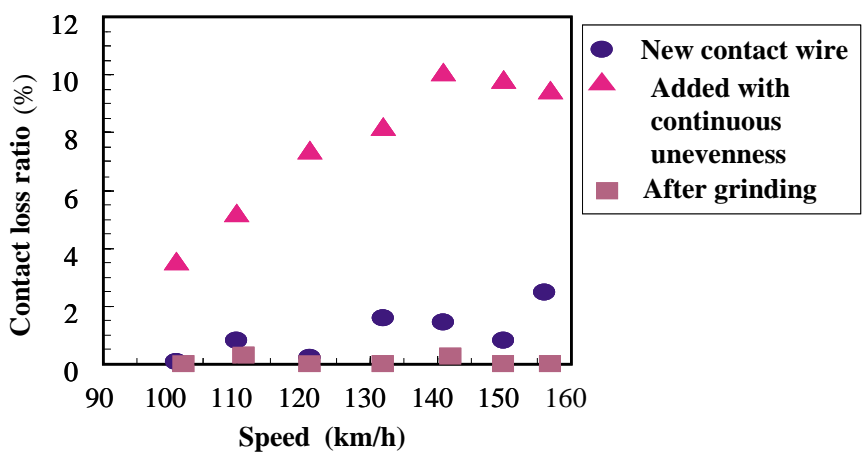

Fig. 5 Contact loss ratio of T-type cross-section rigid conductor lines

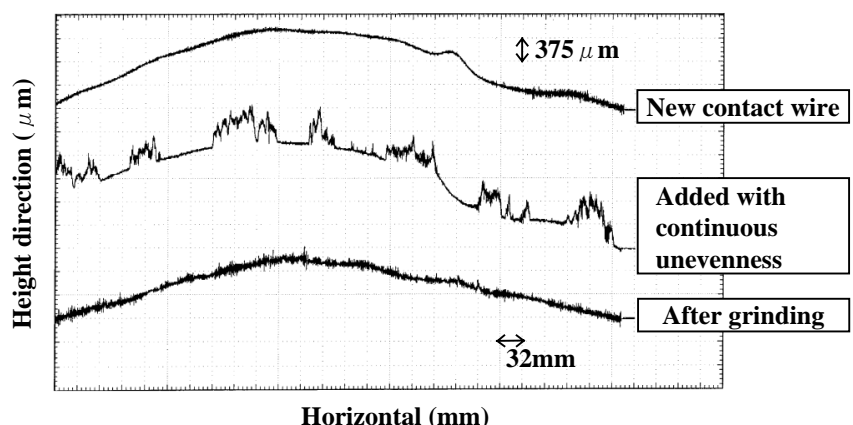

Fig. 6 Waveforms of contact surface (at support)

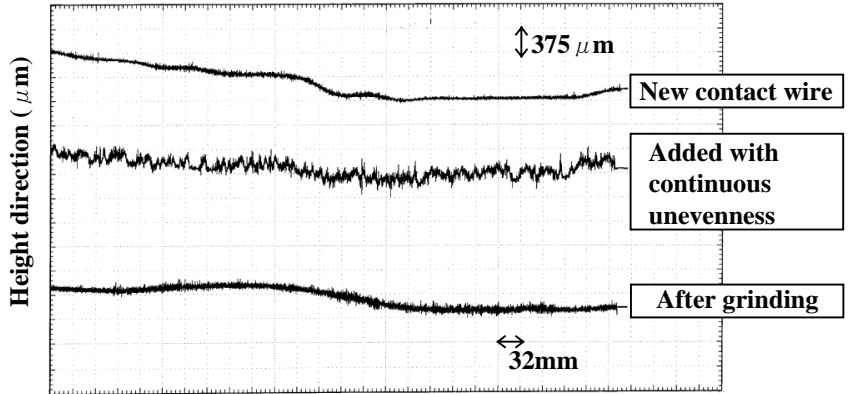

Horizontal (mm)

Fig. 7 Waveforms of contact surface (supports between)

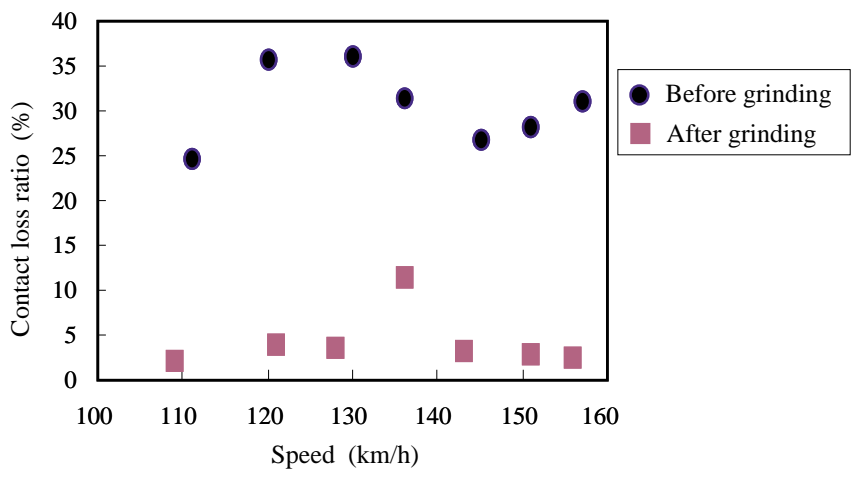

Fig. 8 Contact loss ratio of rigid conductor lines of the flexure type

$\mathrm{km} / \mathrm{h}$. Contact wire manufacturers wind new contact wires around a drum after manufacture for storage. Therefore, new contact wires have small unevenness due to the winding on the contact surface. At a speed higher than $100 \mathrm{~km} / \mathrm{h}$, we believe contact loss occurs by the unevenness generated in the above process.

Next, we added continuous unevenness to the contact surface to imitate the corrugation generated by train operation to find that the contact loss ratio increased more sharply than in the case of the new contact wire. When the unevenness of contact surface was ground by the grinding machine, the contact loss ratio was about 0 $\%$ at $160 \mathrm{~km} / \mathrm{h}$. Thus, we were able to confirm the good quality of current collection.

Moreover, we formed corrugation at an amplitude of about $0.5 \mathrm{~mm}$ by using the grinder, and performed grinding operation. The grinding machine can grind unevenness when the operation is performed about six times (Figs. 6 and 7).

\subsection{Rigid conductor lines of the flexure type}

We installed the rigid conductor lines of the flexure type on the current collection testing equipment at the Railway Technical Research Institute. Figure 8 shows the contact loss ratios at different speeds. In addition, the structure of rigid conductor lines of the flexure type is the same as that of the rail type rigid conductor lines. In the state before grinding, the contact loss ratio was as high as $20-36 \%$, which reduced to $2-12 \%$ at $160 \mathrm{~km} /$ $\mathrm{h}$ after removal by the grinding machine. For the contact surface that has unevenness of small amplitude and 
wavelength, the contact loss ratio was better than before grinding.

\subsection{Unevenness ground by the grinding machine}

As mentioned above, unevenness that the grinding machine can smooth are minute unevenness generated on the contact surface. Figure 9 shows the types of unevenness that can be ground by the grinding machine. The unevenness of contact surface of welding joints and corrugations are reported to be about $0.1 \mathrm{~mm}$ in amplitude. Although the grinding capability of the grinding machine depends on the width of target rigid conductor lines, it can grind unevenness of $0.1 \mathrm{~mm}$ by repeating grinding operation once or twice, in the case of T-type cross-section rigid conductor lines in Fig. 1 . The grinding machine cannot remove deep cracks shown in Fig. 9. However, we thought that there were few possibilities of generating such a deep crack except at manufacture or installation.

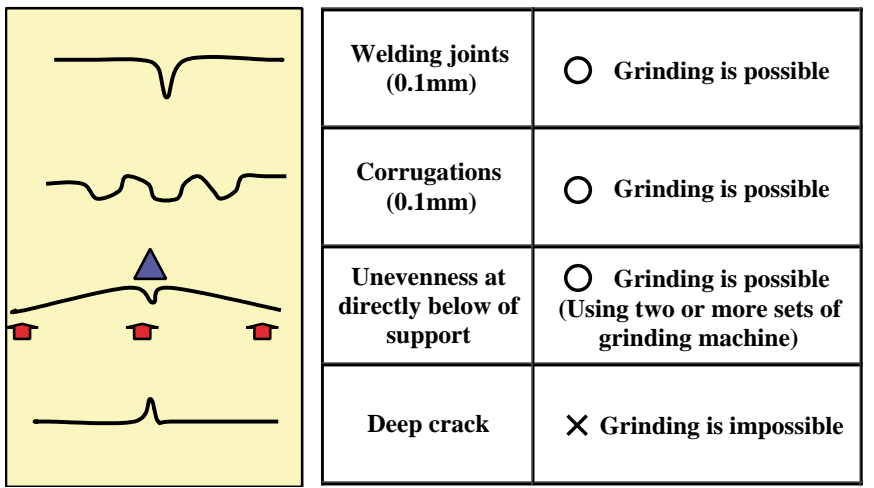

Fig. 9 Types of unevenness that grinding machine can grind

\subsection{Grinding method for support point}

Inclination tends to become large just under a support point because of the mass of rigid conductor line. For the reason, the grinding machine may be unable to grind minute unevenness especially when the distance between support points is large. In this case, rigid conductor lines are pushed up by using two or more sets of the grinding machines. We can also make the bend of rigid conductor lines smaller to make it in the same form as in the case where support intervals are short. We obtained two conclusions as the result of grinding imitation examination for the T-type cross-section rigid conductor lines.

(1) We used two or more grinding machines, and confirmed that the grinding machines could grind the contact surface just under a support point by pushing up rigid conductor lines.

(2) We confirmed that a grinding machine could smooth the contact surface at support intervals of about 12 $\mathrm{m}$. The grinding machine can push with a maximum force of about $500 \mathrm{~N}$, which is equivalent to the mass of about $8 \mathrm{~m}$-long rigid conductor lines.

\section{Conclusions}

We developed a grinding machine for the purpose of grinding unevenness and reducing contact loss. By testing the quality of current collection by using the grinding machine, we have found that the contact loss ratio can sharply be reduced for any rigid conductor line of rigid flexure or T-type. Therefore, it is believed that rigid conductor lines can be used for the high speed operation at $160 \mathrm{~km} / \mathrm{h}$ by managing the contact surface appropriately. 